\title{
Mutations in the Wilms' Tumor 1 Gene Cause Isolated Steroid Resistant Nephrotic Syndrome and Occur in Exons 8 and 9
}

\author{
BETTINA MUCHA, FATIH OZALTIN, BERNWARD G. HINKES, KATRIN HASSELBACHER, RAINER G. RUF, \\ MICHAEL SCHULTHEISS, DANIELA HANGAN, BETHAN E. HOSKINS, ANNE SCHULZE EVERDING, \\ RADOVAN BOGDANOVIC, THOMAS SEEMAN, BERND HOPPE, \\ FRIEDHELM HILDEBRANDT, AND MEMBERS OF THE APN STUDY GROUP*
}

\begin{abstract}
Departments of Pediatrics and Communicable Diseases, and Human Genetics [B.M., F.O., B.G.H., K.H., D.H., B.E.H., F.H.], University of Michigan, Ann Arbor, Michigan 48109; Department of Pediatrics [B.M.], Albany Medical Center, Albany, New York 12208; Department of Pediatric Nephrology [F.O.], Hacettepe University Faculty of Medicine, Ankara, Turkey; Department of Cardiology [R.G.R.], Franz-Volhard-Klinik, Campus Berlin-Buch, 13125 Berlin, Germany; University of Freiburg [M.S.], 79085 Freiburg, Germany; University Children's Hospital [A.S.E.], Muenster, 48149 Muenster, Germany; Institute of Mother and Child Health [R.B.], Belgrade 11070, Republic of Serbia and Montenegro; Department of Pediatrics [T.S.], University Hospital Motol, 15006 Prague 5, Czech Republic; Department of Pediatric Nephrology [B.Ho.], University Children's Hospital, 50924 Cologne, Germany
\end{abstract}

\begin{abstract}
Primary steroid-resistant nephrotic syndrome (SRNS) is characterized by childhood onset of proteinuria and progression to end-stage renal disease. Approximately $10-25 \%$ of familial and sporadic cases are caused by mutations in NPHS2 (podocin). Mutations in exons 8 and 9 of the WTI gene have been found in patients with isolated SRNS and in SRNS associated with Wilms' tumor (WT) or urogenital malformations. However, no large studies have been performed to date to examine whether WTI mutations in isolated SRNS are restricted to exons 8 and 9. To address this question, we screened a worldwide cohort of 164 cases of sporadic SRNS for mutations in all 10 exons of the WTI gene by multiplex capillary heteroduplex analysis and direct sequencing. NPHS2 mutations had been excluded by direct sequencing. Fifteen patients exhibited seven different mutations exclusively in exons 8 and 9 of
\end{abstract}

Received June 10, 2005; accepted September 9, 2005.

Correspondence: Friedhelm Hildebrandt, M.D., University of Michigan Health System, 8220C MSRB III, 1150 West Medical Center Dr., Ann Arbor, MI 48109-0646; e-mail: fhilde@umich.edu

*Members of the Study Group of the Arbeitsgemeinschaft für Pädiatrische Nephrologie: J. Thaarup (Aalborg, Denmark); A. Noyan (Adana, Turkey); A. Bakkaloglu, S. Kalman (Ankara, Turkey); J. Hopcian (Ann Arbor, MI); K. Van Hoeck (Antwerp, Belgium); G. Gorman (Baltimore, MD); F. Burkhalter, B. Descoendres, M. Mayr (Basel, Switzerland); A. Peco-Antic, J. Putnik, N. Stajic (Belgrade, Serbia and Montenegro); S. Briese, J. Gellermann, U. Querfeld (Berlin, Germany); H. Bachmann (Bremen, Germany); J. Springate (Buffalo, NY); G. Reusz (Budapest, Hungary); A. Goldberg (Chicago, IL); C. Licht, D. Michalk, L. Stapenhorst (Cologne, Germany); M. Gahr, G. Kvaldova, M. Laa $\beta$ (Dresden, Germany); W. Rascher (Erlangen, Germany); P. Hoyer (Essen, Germany); U. Neyer (Feldkirch, Austria); M. Brandis, A. Fuchshuber, C. von Schnakenburg (Freiburg, Germany); C. Mache (Graz, Austria); L. Patzer (Halle, Germany); M. Kemper, D.E. Müller-Wiefel (Hamburg, Germany); J.H.H. Ehrich, D. Hohmann, G. Offner (Hannover, Germany); S. Skalova (Hradec Kralove, Czech Republic); F. Schäfer, T. Knüppel, O. Mehls, B. Tönshoff, D. Wenning (Heidelberg, Germany); H. Patzer, G. Rönnefarth (Jena, Germany); R. Cohen-Becker (Jerusalem, Israel); J. Scheinman (Kansas City, MO); S. Hashmi (Karachi, Pakistan); P. Eggert (Kiel, Germany); R. Ettenger, L. Rangel (Los Angeles, CA); S. Wygoda (Leipzig, Germany); R. Beetz (Mainz, Germany); F. Anacleto (Manila, Philippines); H. Fehrenbach (Memmingen, Germany); K. Timmermann (Moers, Germany); M. Griebel (Munich, Germany); G. Filler (Ottawa, Canada); S. Pavicevic (Podgorica, Serbia and Montenegro); J.Muscheites, G. Warnecke (Rostock, Germany); N. Benador (San Diego, CA); J. Monterrode Pina Neto (Sao Paulo, Brazil); M. Lilova (Sofia, Bulgaria); M. Bald, M. Holder, H. Leichter (Stuttgart, Germany); A. Zolotnitskaya, R. Weiss (Valhalla, NY); A. Pollak (Vienna, Austria); G. Laube, T. Neuhaus (Zurich, Switzerland)

Support for this project was received from the National Kidney Foundation of Michigan (Ann Arbor, MI) and from the MD Foundation (Ann Arbor, MI).

DOI: 10.1203/01.pdr.0000196717.94518.f0-
WT1. Although it is possible that pathogenic mutations of WT1 may also reside in the introns, regions of the gene that were not able to be screened in this study, these data together with our previous results (Ruf et al.: Kidney Int 66: 564-570, 2004) indicate that screening of WT1 exons 8 and 9 in patients with sporadic SRNS is sufficient to detect pathogenic WT1 mutations and may open inroads into differential therapy of SRNS. (Pediatr Res 59: 325-331, 2006)

$\mathrm{P}$ rimary SRNS is a clinically and genetically heterogeneous disease. Histology phenotypes include focal segmental glomerulosclerosis (FSGS) in 80\%, minimal change nephrotic syndrome (MCNS) in 20\%, and, rarely, diffuse mesangial sclerosis (DMS). Advances have been made in the understanding of SRNS pathogenesis through positional cloning of genes causing nephrotic syndrome (NPHS1, NPHS2, $\alpha$-actinin-4, and $C D 2 A P$ ). The encoded proteins nephrin, podocin, $\alpha$-actinin-4, and CD2AP are integral components of the slit membrane of the glomerular podocyte. Whereas NPHS1 mutations seem to exclusively cause congenital nephrotic syndrome, NPHS 2 mutations have been identified in congenital, childhood and adult onset SRNS (1-5) and accounted for $26 \%$ of all SRNS patients in one study (3) and 10\% of sporadic and $43 \%$ of familial cases in a second (5). Several small studies and case reports have been published on WT1 mutations in patients with isolated SRNS (6-11) or associated with urogenital malformations $(8,12-17)$. WT1 mutations occurred mainly in exons 8 and 9, which code for zinc finger domains 2 and 3, respectively. A possible connection between the structural protein nephrin and the transcription factor WT1 is the finding that WT1 transcriptionally activates the NPHSI promoter, resulting in up-regulation of nephrin mRNA $(18,19)$. WT1 was originally identified as the gene responsible

\footnotetext{
Abbreviations: DDS, Denys-Drash syndrome; DMS, diffuse mesangial sclerosis; ESRD, end-stage renal disease; FS, Frasier syndrome; FSGS, focal segmental glomerulosclerosis; MCHA, multiplex capillary heteroduplex analysis; MCNS, minimal change nephrotic syndrome; SRNS, steroid-resistant nephrotic syndrome; WT, Wilms' tumor
} 
for the childhood kidney cancer Wilms' tumor (WT) $(20,21)$. Denys-Drash syndrome (DDS) $(22,23)$ and Frasier syndrome (FS) (24) were then shown to be caused by WT1 mutations in patients with an XY karyotype $(13,25)$. Recently, our group conducted a study on 115 sporadic SRNS and 110 sporadic steroid-sensitive nephrotic syndrome (SSNS) cases, which focused on WT1 exons 6-9 (26). Only mutations in exons 8 and 9 were identified in $6 \%$ of individuals with isolated SRNS and predominantly an XX karyotype. For WT, Royer-Pokora et al. (27) recently published a study on 117 children with WT1 germline mutations located in all 10 exons of the gene. To address the question whether mutations associated with SRNS also occur throughout $W T 1$, we screened a worldwide cohort of 167 patients (121 new; 46 previously examined for exons 6-9 by us) for all 10 exons of WT1 using MCHA and direct sequencing.

\section{MATERIALS AND METHODS}

Materials. Blood samples, clinical data, and informed consent were obtained from patients and their parents. Genomic DNA was isolated from blood samples using standard methods (28). Ethics approval was obtained from the ethics committee of the University of Freiburg (Freiburg, Germany) and the Internal Review Board of the University of Michigan (Ann Arbor, MI). The diagnosis of SRNS was established by pediatric nephrologists at different centers according to published criteria (29). For clinical evaluation a standard questionnaire was used (4). Forms are accessible at www.renalgenes.org. Patients with a familial form of nephrotic syndrome or disease causing mutations in the NPHS2 or NPHS1 gene were not included. Minimal clinical diagnostic criteria to define SRNS were proteinuria, histologic diagnosis of chronic glomerulonephritis, and lack of response to standard steroid therapy. Additional non-exclusive features noted were age at onset of proteinuria and extrarenal manifestations, e.g. genitourinary tract malformations. Response to steroid treatment was defined according to the International Study of Kidney Disease in Children and Arbeitsgemeinschaft für Pädiatrische Nephrologie guidelines (29). All patients in this study with primary SRNS had an age of onset of 18 y or younger. Of these 167 patients, results have been partially published by Ruf et al. (26) for 46 patients. Patients' ethnic background was central European, Turkish, African-American, Hispanic, or Asian.

Heteroduplex analysis. All patients underwent exon PCR and direct sequencing of exons 8 and 9 of the WT1 gene as described in Ruf et al. (26). A group of 167 patients were analyzed by MCHA according to the recommendations in the original article (30) for exons 2-10 of WT1. For primer sequences, fragment length, and fluorescent labeling, see Table 1. Products of three exons with different fragment lengths and fluorescent labeling were pooled for every individual yielding three panels (exons 2, 4, and 7; exons 8, 9, and 10; exons 3, 5, and 6). Samples were run on a MegaBACE 1000 DNA Analysis System (Amersham Biosciences, Little Chalfont, Buckinghamshire, UK) and evaluated with Genetic Profiler software version 1.1 (Molecular Dynamics, Sunnyvale, CA).

Direct sequencing. Due to its high GC content (70\%) and product length, exon 1 was considered unsuitable for MCHA. Therefore, this exon was evaluated by direct sequencing of both strands for all 167 patients, as were exons 8 and 9. Also, samples that yielded an aberrant peak pattern or insufficient peak height in MCHA were amplified and analyzed by direct sequencing of the forward strand using the primers in Table 1 (without fluorescent label). Sequences were analyzed using Sequencher version 4.1.4 software (GeneCode, Ann Arbor, MI).

\section{RESULTS}

Mutations. In total, we detected five different WTI mutations in six new patients and two different mutations in the previously published group of WTI patients (Table 2) (26). All seven different mutations cause changes in the running pattern of the fragments of exons 8 and 9 and were detected by MCHA in all 12 patients. One novel sequence variant was found to cause an amino acid change in exon 9 (P382S) and will be discussed separately. We also detected 14 different WT1 polymorphisms (see Table 3) of which seven were located in exon 1, three in exon 3, and one each in exons 2, 5, 7, and 8. Polymorphisms in exons 7 and 8 were not detected by MCHA analysis and were only found by sequencing. Nine variants are known SNP, according to the UCSC database May 2004 freeze (http://genome.ucsc.edu), five nonpathogenic sequence variants are not described there and are either located in the intron or cause exonic base changes without consequence at the amino acid level (see Table 3). In WTI exon 8 we detected two heterozygous missense mutations: c.1079G $>$ A C360Y in patient A201 and c.1119C $>$ A H373Q in patient A644 (Table 2). C360Y has been described previously in a female patient with a diagnosis of DDS (12). H373Q has been recently published for a patient with WT (27). By MCHA, both samples showed shouldered peak patterns as expected (Fig. 1). In WTI exon 9, five different heterozygous mutations were detected in 10 patients from different families (see Table 2). Mutation H401R in patient A133 is not previously described, but a different mutation affecting the same codon $(\mathrm{H} 401 \mathrm{Y})$ has been identified in a female patient with DDS nephropathy and unilateral WT (31). This base change was not found in 90 healthy controls from central Europe. The point mutation c.1162T $>$ C C388R in patient F1031 has been published by Ruf et al. (26). c.1180C $>$ T R394W was first described by Pelletier et al. (25) and has been found frequently in patients with DDS and WT $(8,11,32-34)$. All three point mutations affect the third zincfinger domain (amino acids 383-405). In the other seven patients, we identified two different splice site mutations: three patients were heterozygous for IVS9 $+4 \mathrm{C}>\mathrm{T}$ and four patients were heterozygous for IVS9 $+5 \mathrm{G}>\mathrm{A}$. IVS $9+$

Table 1. Primer sequences used for MCHA and direct sequencing

\begin{tabular}{lllcc}
\hline & \multicolumn{1}{c}{ Forward $\left(5^{\prime}\right.$ to $\left.3^{\prime}\right)$} & \multicolumn{1}{c}{ Reverse $\left(5^{\prime}\right.$ to $\left.3^{\prime}\right)$} & Product length (bp) \\
\hline Exon 1 & CCTACAGCAGCCAGAGCAG & TAAGAGCTGCGGTCAAAAGG & 677 & 365 \\
Exon 2 & GGCTGGTTCAGACCCACTG & AGGGAGACCCAGTCTTGTCC & 239 & NA \\
Exon 3 & GCTCAGGATCTCGTGTCTCC & GGTCCCAAGGACCCAGAC & 217 & FAM \\
Exon 4 & TCCATTGCTTTTGAAGAAACAG & CTTTGAAATGGTTCAAACAGG & 320 & 304 \\
Exon 5 & CAGTGGGACTGGGGACTTAG & TCCCATCCACCAAATGCTAC & 281 & FAM \\
Exon 6 & CCATCATTCCCTCCTGATTG & AGCCTGCAGTGAAGAAGAGG & 351 & HEX \\
Exon 7 & AAGACCTACGTGAATGTTCAC & GTGTGAGAGCCTGGAAAAGG & HEX \\
Exon 8 & CCTTTAATGAGATCCCCTTTCC & GGGGAAATGTGGGGTGTTTCC & FAM \\
Exon 9 & CCTCACTGTGCCCACATTGT & GCACTATTCCTTCTCTCAACTGAG & HEX \\
Exon 10 & CTTCACTCGGGCCTTGATAG & GCTGCCTGGGACACTGAAC & 238 & FAM \\
\hline
\end{tabular}

NA, not applicable. 
MUTATIONS IN WT1 EXONS 8, 9 CAUSE SRNS

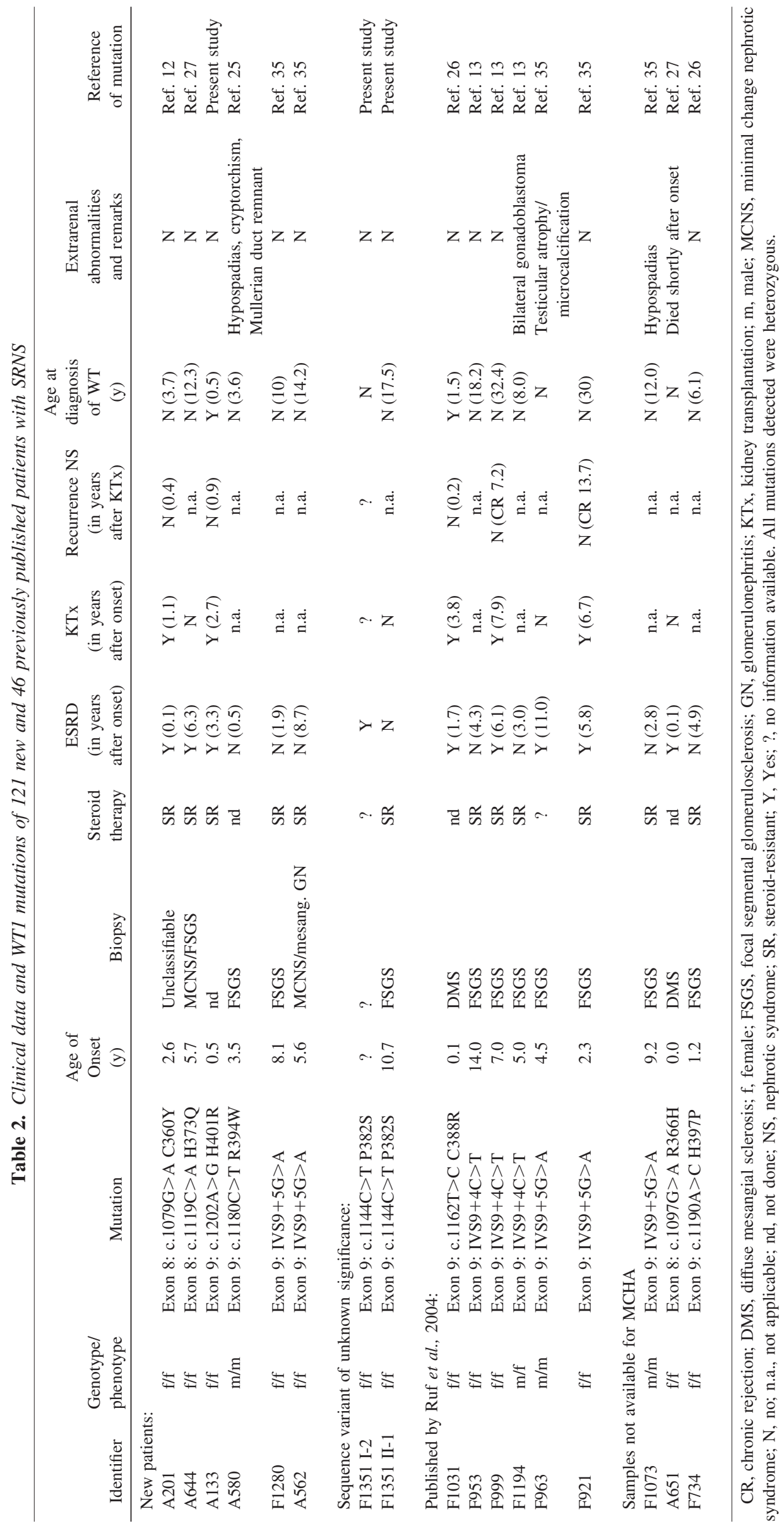


Table 3. Innocuous Polymorphisms of WT1 in a worldwide cohort of 164 SRNS patients

\begin{tabular}{|c|c|c|c|}
\hline & Heterozygous & Homozygous & $\begin{array}{c}\text { Accession number of } \\
\text { known polymorphisms } \\
\text { (UCSC May } 2004 \text { freeze) }\end{array}$ \\
\hline \multicolumn{4}{|c|}{ Exon 1: sequences of 138 patients evaluated } \\
\hline 5'-UTR: $-39 \mathrm{C}>\mathrm{A}$ & 1 & 0 & dbSNP rs2234581 \\
\hline 5'-UTR: $-7 \mathrm{G}>\mathrm{T}$ & 46 & 8 & dbSNP rs2234582 \\
\hline $\mathrm{C} 117 \mathrm{~T}$ (silent) & 1 & 0 & Present study \\
\hline C126T (silent) & 40 & 8 & dbSNP rs1799925 \\
\hline C162G (silent) & 2 & 0 & Present study \\
\hline C390T (silent) & 19 & 1 & dbSNP rs2234583 \\
\hline IVS $1+13 \mathrm{G}>\mathrm{C}$ & 1 & 0 & Present study \\
\hline \multicolumn{4}{|l|}{ Exon 2} \\
\hline $\mathrm{IVS} 2+17 \mathrm{~A}>\mathrm{G}$ & 1 & 0 & Present study \\
\hline \multicolumn{4}{|c|}{$\begin{array}{l}\text { Exon 3: heteroduplexing results of } 328 \text { base } \\
\text { fragment for } 93 \text { patients }\end{array}$} \\
\hline $\mathrm{IVS} 3+16 \mathrm{G}>\mathrm{A}$ & 10 & 0 & dbSNP rs1799933 \\
\hline $\mathrm{IVS} 3+82 \mathrm{G}>\mathrm{T}$ & 25 & 4 & dbSNP rs5030170 \\
\hline $\mathrm{IVS} 3+85 \mathrm{G}>\mathrm{C}$ & 25 & 4 & dbSNP rs5030171 \\
\hline \multicolumn{4}{|l|}{ Exon 5} \\
\hline IVS5 $+37 \mathrm{G}>\mathrm{T}$ & 1 & 0 & Present study \\
\hline \multicolumn{4}{|c|}{ Exon 7: sequencing results of 8 patients evaluated } \\
\hline A903G (silent) & 5 & 0 & dbSNP rs 16754 \\
\hline \multicolumn{4}{|c|}{ Exon 8: 78 samples evaluated for IVS-32C $>A$} \\
\hline IVS7-32C $>A$ & 12 & 2 & dbSNP rs2234593 \\
\hline \multicolumn{4}{|l|}{ Exon 9} \\
\hline C1144T (P382S) & 1 & 0 & Present study \\
\hline
\end{tabular}

All 164 patients were included in heteroduplex analysis of exons 2-10. All patients were examined by direct sequencing of exons 1,8 , and 9 . Only 138 sequences of exon 1 were completely evaluated for quality purposes. MCHA of exon 3 was done in two steps: 93 patients were analyzed with a 328 base fragment, 71 with a smaller 239 base fragment excluding dbSNPs rs5030170 and rs5030171. MCHA of exon 7 did not detect A903G which was found by sequencing eight patients for quality purposes. Sequencing of exon 8 yielded 78 samples of sufficient quality to evaluate for IVS7-32C $>$ A.

$4 \mathrm{C}>\mathrm{T}$ was first described by Barbaux et al. (13) in a patient with FS and an XY karyotype. IVS9 + 5G>A has been associated with DDS nephropathy, WT, or gonadoblastoma $(11,35,36)$.

All mutations were detected by MCHA and exhibited running patterns distinct from the wild-type sequence. The running patterns were characteristic for specific mutations: The samples of the three patients with IVS $9+4 \mathrm{C}>\mathrm{T}$ showed a double peak, whereas the peaks of the four patients with IVS9 $+5 \mathrm{G}>\mathrm{A}$ all had shouldered peaks.

New sequence variant P382S in family F1351 in WT1 exon 9. Sequencing of exon 9 in patient F1351 II-1, a girl from Montenegro with isolated SRNS, showed a not previously described heterozygous base exchange, c.1144C $>\mathrm{T}$, leading to the nonconservative substitution of a proline for a serine at position 382 of the WT1 protein (Table 2). This base change was not found in any of the other 163 patients nor in 90 healthy controls from central Europe. This is not a de novo mutation inasmuch as it was also present in her mother who suffers from end-stage renal disease of unknown primary cause and a healthy 20 -y-old sister (Fig. $2 A$ ). The proline to serine substitution is from a hydrophobic side chain to a noncharged polar side chain. This proline is highly conserved in mouse, rat, Danio rerio,
Drosophila melanogaster, Caenorhabditis elegans, and Saccharomyces cerevisiae and is located directly next to zinc finger domain 3 (amino acids 383-405, Swiss-Prot entry P19544) (Fig. 2B).

No known SNP are located within the amplicon sequence for exon 9 according to UCSC and no other polymorphisms were detected in exon 9 by sequencing or MCHA.

Clinical data. Of the 167 patients included in this study, all had SRNS. Data on 46 patients have been published previously (26). A total of 15 patients with WT1 mutations in exons 8 and 9 were identified by direct sequencing. Eight of these patients had been identified and published by Ruf et al. (26). A new group of 121 patients (59 female, 62 male), with nonfamilial SRNS was identified from our database. Informed consent had been given. In this group, seven (5.8\%) new patients with WT1 mutations in exons 8 and 9 were identified, $6 / 59$ female (10.2\%) and one male patient with genitourinary tract malformations (see Table 2). In total, nine patients out of a group of 229 patients with nonfamilial isolated SRNS were identified with $W T 1$ mutations (3.9\%). Including patients with genitourinary tract malformations and WT increases the rate to 15 out of 235 patients $(6.3 \%)$.

MCHA for exons 2-10 was performed with 164 samples, of which 38 samples belonged to patients who had been included 

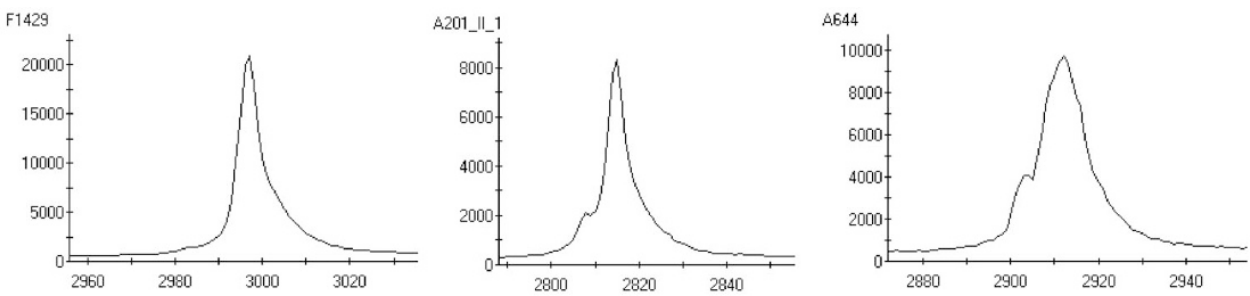

Figure 1. Examples of MCHA results exon 8. A201 II-1 (A201_II_1) and A644 carry heterozygous point mutations causing a shoulder pattern in MCHA. Individual identifiers are located in the left upper corners. The horizontal axis denotes scan points, the vertical axis denotes the relative peak intensity. Because no length standard was used, scan points cannot be compared between different samples. F1429 is a control individual yielding the wild type MCHA pattern for comparison.

in Ruf et al. (26) and who did not have any mutation in WT1 exons 7-9, and 114 new SRNS patients.

One patient, F1351 II-1, with a previously unpublished sequence change in exon 9 was also included in this study although her mother was reported to suffer from end stage renal failure of unknown pathogenesis (see Fig. $2 A$ and Table 2 ). The other 151 patients did not have any affected family members. None of the patients without pathogenic mutations in exon 8 or 9 exhibited mutations in other exons.

For the evaluation of the clinical data, three additional patients (A651, F734, F1073) with WT1 mutations who were not available for MCHA were included (see Table 2). In the group of 15 patients with $W T 1$ mutations $\left(W T 1^{+}\right)$, ten patients had isolated SRNS without genitourinary tract malformations and without diagnosis of WT at the time of enrollment in the study. All 10 patients were phenotypically female, 7/10 exhibited FSGS on kidney biopsy. Data on 8/15 patients has been published previously by Ruf et al. (26). Seven patients with WT1 mutations were part of 120 new patients collected worldwide (see Table 2). Only three patients with a male phenotype and WT1 mutations were identified, leading to a female:male ratio of $4: 1$ in the $W T 1^{+}$group. In the group without $W T 1$ mutations $\left(W T 1^{-}\right)$, the gender distribution was 1:1.2. The median age of onset of proteinuria was $5.8 \mathrm{y}$ compared with 4.7 y in the $W T 1^{+}$group. The percentage of patients in the $\mathrm{WTI}^{-}$group who developed ESRD was $26 \%$ (40/152) compared with $53 \%(8 / 15)$ in the $W T 1^{+}$group. Median age at ESRD was $13.7 \mathrm{y}$ in the $W T 1^{-}$group versus 8.1 $\mathrm{y}$ in the $\mathrm{WTI}^{+}$group, but with a shorter time interval between clinical diagnosis of proteinuria and ESRD. Histology phenotypes were comparable in both groups (see Table 4).
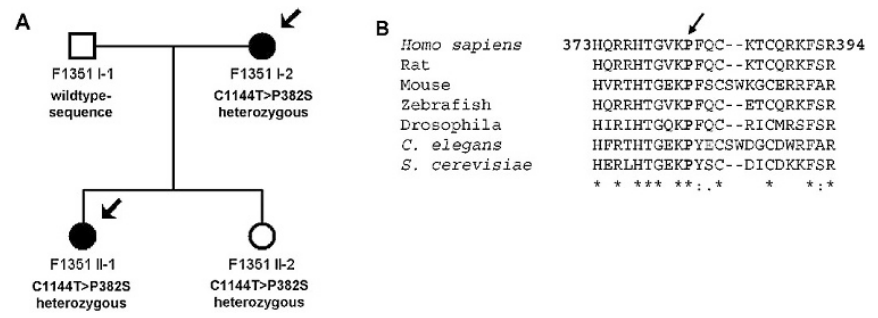

Figure 2. Sequence variant of unknown significance in F1351. (A) Pedigree of F1351 and sequencing results. Squares denote males, circles females; filled symbols indicate renal disease; arrows denote individuals included in MCHA. (B) Conservation of P382 (arrow) in the Wt1 protein of different species. The conserved proline is located C-terminal to the first amino acid of zinc finger domain 3 (F383).

\section{DISCUSSION}

In this study, we addressed the question whether a significant number of patients in a worldwide cohort of 152 with isolated SRNS and no mutations in nephrin (NPHSl) or podocin (NPHS2) have WT1 mutations outside the known "hotspot" regions in exon 8 and 9. We identified six different WT1 mutations in seven patients of a worldwide cohort of 120 new patients with isolated SRNS. In addition, we identified a novel base change (P388S) at the border of the third zincfinger domain of WT1. We demonstrate that mutations in this SRNS cohort and 44 additional patients previously examined for exons 6-9 (26) are restricted to WT1 exons 8 and 9.

Within our on-going study project, sequencing of exons 8 and 9 in patients with SRNS lead to the identification of 15 patients with mutations in exons 8 and 9 . Ten patients suffered from isolated nephrotic syndrome and had a female phenotype (see Table 2 and ref. 26). If numbers in Royer-Pokora's study in patients with Wilms' tumor were equivalent to patients with isolated SRNS, we would have expected to identify 8 patients with WT1 mutations in exons 1-7 or 10 (equivalent to $45 \%$ ) in addition to our 10 patients with isolated SRNS that had mutations in exon 8 and 9 (equivalent to 55\%). However, direct sequencing and MCHA did not detect any pathogenic mutation in exons 1-7 or exon 10 in 151 patients with isolated SRNS.

One new sequence variant of unknown significance and five new sequence variants. One base exchange not previously described, c.1144C $>$ T P382S, was identified. Although determining its significance is difficult, several factors favor the notion that it might cause nephrotic syndrome in this family: 1) It was not found in 90 healthy controls from central Europe. 2) It segregates with the affected mother I-2 and daughter II-1 (Fig. 2A). 3) It affects an amino acid highly conserved in evolution. Although not part of a zinc-finger domain, the change from a nonpolar hydrophobic amino acid to an uncharged polar amino acid and its location immediately $\mathrm{N}$-terminal to zinc-finger domain 3 suggests that it might disrupt the structure and function of WT1 transcriptional activity.

Arguments that this may be an innocuous polymorphism are as follows: 1) The so-far healthy 20-y-old sister II-2 carries the same heterozygous base change (Fig. 2A) but future onset of nephrotic syndrome cannot be excluded. 2) Phenotypic data of the mother is scarce and a cause of ESRD other than primary SRNS cannot be excluded. She presented with 
Table 4. Clinical data on 167 SRNS patients

\begin{tabular}{|c|c|c|c|c|c|c|c|}
\hline Group & $\begin{array}{l}\text { No. of } \\
\text { patients }\end{array}$ & $\begin{array}{c}\text { Female/male } \\
\text { ratio }(\%)\end{array}$ & $\begin{array}{l}\text { Median age } \\
\text { of onset } \\
\text { (y) }\end{array}$ & $\operatorname{ESRD}(\%)$ & $\begin{array}{l}\text { Median age } \\
\text { at ESRD } \\
(\mathrm{y})\end{array}$ & $\begin{array}{c}\text { ESRD after onset } \\
\text { of proteinuria } \\
\text { (median years) }\end{array}$ & $\begin{array}{c}\text { Biopsy } \\
\text { FSGS/MCNS/other*/ND } \\
(\%)\end{array}$ \\
\hline Presence of $W T 1$ mutation $\left(W T 1^{+}\right)$ & $15 / 167$ & $12 / 3(80 / 20)$ & 4.5 & $8 / 15(53.3)$ & 6.0 & 4.6 & $9 / 2 / 3 / 1(60 / 13 / 20 / 7)$ \\
\hline Absence of $W T 1$ mutation $\left(W T 1^{-}\right) \dagger$ & $152 / 167$ & $68 / 84(45 / 55)$ & 5.8 & $40 / 152(26.0)$ & $13.7 \ddagger$ & $2.9 \S$ & $96 / 31 / 13 / 12(63 / 20 / 9 / 8)$ \\
\hline Total of SRNS patients & 167 & $80 / 87(48 / 52)$ & 5.5 & $48 / 167(28.7)$ & $13.0 \mathrm{I}$ & $3.3 \|$ & $105 / 33 / 16 / 12(63 / 20 / 10 / 7)$ \\
\hline
\end{tabular}

DMS, diffuse mesangial sclerosis; FSGS, focal segmental glomerulosclerosis; MCNS, minimal change nephrotic syndrome; MPGN, mesangio proliferative glomerulonephritis; ND, not done.

* Includes DMS, IgG- and IgM-nephropathy, MPGN.

$\dagger$ Including F1351 II-1.

$\ddagger$ Incomplete data on $2 / 40$ patients.

$\S$ Incomplete data on $6 / 40$ patients.

II Incomplete data on $2 / 48$ patients.

|| Incomplete data on $6 / 48$ patients.

renal insufficiency at age $30 \mathrm{y}$ leading to end-stage renal failure $1 \mathrm{y}$ later. 3) Whereas the great majority of described mutations in WTI are de novo mutations, this change could be another rare example of a transmitted WT1 mutation. There are few reports on familial cases of WT1 mutations (37-39). A mother with isolated proteinuria and preserved renal function carried IVS9 $+5 \mathrm{G}>$ A heterozygously and transmitted it to her daughter who was diagnosed with nephrotic syndrome at the age of 9 mo (39). In the other two case reports, siblings with WT inherited heterozygous truncating mutations from phenotypically unaffected parents $(37,38)$. Functional studies will be necessary to finally determine the significance of this new base change c.1144C $>\mathrm{T}$. The other five base changes not previously described were classified as nonpathogenic, because of their localization in intronic sequence or because of their silent character. Also identified were eight known SNP (see Table 3).

Genotype-phenotype correlations. The predominant phenotype on kidney biopsy in our patient population was FSGS. In fact, clinical data on 7/120 patients from this study and 8/125 patients from a previous study (see Table 2) shows that the histology phenotype of patients with WT1 mutations is not DMS. Age of onset of proteinuria and/or edema was highly variable with congenital cases of SRNS (A651 and F1031), as well as in one juvenile patient (F953), even between patients with the same mutation. WT1 mutations lead to ESRD in 7/15 patients after a variable period of time. Whereas A651 suffered renal failure at onset and died shortly thereafter of sepsis, F963 developed ESRD 11 y after onset of proteinuria. Of the five children that received a kidney transplant, none suffered recurrence of nephrotic syndrome with less than $1 \mathrm{y}$ follow-up in three patients. Patients F921 and F999 lost the transplanted kidney after 13 and 7 y respectively due to chronic rejection (Table 2). Although clinical data of 15 patients is not sufficient to draw genotype-phenotype correlations, it already indicates, given the heterogeneity of the patient group in this study, that it may be difficult to demonstrate clear cut genotype/phenotype correlations for WT1 mutations.

Examination of the gender distribution in the $W T 1^{+}$group shows that all patients with isolated SRNS were phenotypically female, whereas males exhibit additional genitourinary tract malformations (see Table 2). In contrast, none of the male patients in the $\mathrm{WTI}^{-}$group had a history of genitourinary tract malformations. One might argue that mainly females have isolated SRNS caused by WT1 mutations and that therefore the selection of SRNS patients in our study has a bias toward the male gender. However, case reports on isolated SRNS in patients with WT1 mutations are rare $(6-10,39)$ and few cases of phenotypically male patients without genitourinary tract malformations have been published $(9,11)$.

Sensitivity of MCHA. In the first publication of MCHA on a MegaBACE, Hoskins et al. (30) achieved a sensitivity of $100 \%$. In our study, sensitivity of MCHA was $91 \%$. The known SNP A903G (dbSNP rs16754) in codon R301 was not detected by MCHA, although it is located 72 bases away from the end of amplicon 7. It is embedded in a GC-rich sequence that could have interfered with its detection (30). In RoyerPokora's study on patients with WT, $12.9 \%$ of all mutations within the WT1 gene (12/93) were located in exon 7 and intron 7 , respectively (27). Three patients with WT had the truncating mutation c.901C $>\mathrm{T} \mathrm{R} 301 \mathrm{X}$. It is not excluded that not only the innocuous silent polymorphism c. $903 \mathrm{~A}>\mathrm{G}$ in exon 7 but also pathogenic mutations affecting the same codon were missed in our patient population.

However, in Royer-Pokora's study (27), 16 of 93 patients with WT1 mutations had heterozygous deletion or insertion mutations that constitutes a rate of $17 \%$. As MCHA has a high sensitivity for insertions and deletions it is unlikely that any deletion or insertion mutations escaped the detection by MCHA in our patient group.

In this study, WT1 mutations in patients with isolated SRNS were detected only in exons 8 and 9. Mutations of WTI outside exons 8 and 9 can therefore only account for a very small proportion of isolated nephrotic syndrome, if at all. In conclusion, we are convinced that a sensitivity of $91 \%$ is extremely high for the rapid and inexpensive screening technique MCHA in comparison to single-stranded conformation polymorphism (SSCP), denaturing HPLC (DHPLC), and other standard methods (30). MCHA is therefore sufficient when screening for mutations in a large group of patients. It should also be sufficient to screen patients for this small group of patients in whom SRNS is caused by WT1 mutations in exons 8 and 9 and allow for directed clinical follow-up and therapy. 


\section{REFERENCES}

1. Tsukaguchi H, Sudhakar A, Le TC, Nguyen T, Yao J, Schwimmer JA, Schachter AD, Poch E, Abreu PF, Appel GB, Pereira AB, Kalluri R, Pollak MR 2002 NPHS2 mutations in late-onset focal segmental glomerulosclerosis: R229Q is a common disease-associated allele. J Clin Invest 110:1659-1666

2. Koziell A, Grech V, Hussain S, Lee G, Lenkkeri U, Tryggvason K, Scambler P 2002 Genotype/phenotype correlations of NPHS1 and NPHS2 mutations in nephrotic syndrome advocate a functional inter-relationship in glomerular filtration. Hum Mol Genet 11:379-388

3. Ruf RG, Lichtenberger A, Karle SM, Haas JP, Anacleto FE, Schultheiss M, Zalewski I, Imm A, Ruf EM, Mucha B, Bagga A, Neuhaus T, Fuchshuber A, Bakkaloglu A, Hildebrandt F; Arbeitsgemeinschaft Fur Padiatrische Nephrologie Study Group 2004 Patients with mutations in NPHS2 (podocin) do not respond to standard steroid treatment of nephrotic syndrome. J Am Soc Nephrol 15:722-732

4. Karle SM, Uetz B, Ronner V, Glaeser L, Hildebrandt F, Fuchshuber A 2002 Novel mutations in NPHS2 detected in both familial and sporadic steroid-resistant nephrotic syndrome. J Am Soc Nephrol 13:388-393

5. Weber S, Gribouval O, Esquivel EL, Moriniere V, Tete MJ, Legendre C, Niaudet P, Antignac C 2004 NPHS2 mutation analysis shows genetic heterogeneity of steroidresistant nephrotic syndrome and low post-transplant recurrence. Kidney Int 66:571579

6. Denamur E, Bocquet N, Baudouin V, Da Silva F, Veitia R, Peuchmaur M, Elion J, Gubler MC, Fellous M, Niaudet P, Loirat C 2000 WT1 splice-site mutations are rarely associated with primary steroid-resistant focal and segmental glomerulosclerosis. Kidney Int 57:1868-1872

7. Dharnidharka VR, Ruteshouser EC, Rosen S, Kozakewich H, Harris Jr, HW Herrin JT, Huff V 2001 Pulmonary dysplasia, Denys-Drash syndrome and Wilms tumor 1 gene mutation in twins. Pediatr Nephrol 16:227-231

8. Schumacher V, Scharer K, Wuhl E, Altrogge H, Bonzel KE, Guschmann M, Neuhaus TJ, Pollastro RM, Kuwertz-Broking E, Bulla M, Tondera AM, Mundel P, Helmchen U, Waldherr R, Weirich A, Royer-Pokora B 1998 Spectrum of early onset nephrotic syndrome associated with WT1 missense mutations. Kidney Int 53:15941600

9. Ito S, Ikeda M, Takata A, Kikuchi H, Hata J, Honda M 1999 Nephrotic syndrome and end-stage renal disease with WT1 mutation detected at 3 years. Pediatr Nephrol 13:790-791

10. Ito S, Takata A, Hataya H, Ikeda M, Kikuchi H, Hata J, Honda M 2001 Isolated diffuse mesangial sclerosis and Wilms tumor suppressor gene. J Pediatr 138:425-427

11. Jeanpierre C, Denamur E, Henry I, Cabanis MO, Luce S, Cecille A, Elion J, Peuchmaur M, Loirat C, Niaudet P, Gubler MC, Junien C 1998 Identification of constitutional WT1 mutations, in patients with isolated diffuse mesangial sclerosis, and analysis of genotype/phenotype correlations by use of a computerized mutation database. Am J Hum Genet 62:824-833

12. Clarkson PA, Davies HR, Williams DM, Chaudhary R, Hughes IA, Patterson MN 1993 Mutational screening of the Wilms's tumour gene, WT1, in males with genital abnormalities. J Med Genet 30:767-772

13. Barbaux S, Niaudet P, Gubler MC, Grunfeld JP, Jaubert F, Kuttenn F, Fekete CN, Souleyreau-Therville N, Thibaud E, Fellous M, McElreavey K 1997 Donor splicesite mutations in WT1 are responsible for Frasier syndrome. Nat Genet 17:467-470

14. Kohsaka T, Tagawa M, Takekoshi Y, Yanagisawa H, Tadokoro K, Yamada M 1999 Exon 9 mutations in the WT1 gene, without influencing KTS splice isoforms, are also responsible for Frasier syndrome. Hum Mutat 14:466-470

15. Melo KF, Martin RM, Costa EM, Carvalho FM, Jorge AA, Arnhold IJ, Mendonca BB 2002 An unusual phenotype of Frasier syndrome due to IVS9 $+4 \mathrm{C}>\mathrm{T}$ mutation in the WT1 gene: predominantly male ambiguous genitalia and absence of gonadal dysgenesis. J Clin Endocrinol Metab 87:2500-2505

16. Kaltenis P, Schumacher V, Jankauskiene A, Laurinavicius A, Royer-Pokora B 2004 Slow progressive FSGS associated with an F392L WT1 mutation. Pediatr Nephrol 19:353-356

17. Hu M, Craig J, Howard N, Kan A, Chaitow J, Little D, Alexander SI 2004 A novel mutation of WT1 exon 9 in a patient with Denys-Drash syndrome and pyloric stenosis. Pediatr Nephrol 19:1160-1163

18. Guo G, Morrison DJ, Licht JD, Quaggin SE 2004 WT1 activates a Glomerularspecific enhancer identified from the human nephrin gene. J Am Soc Nephrol $15: 2851-2856$
19. Wagner N, Wagner KD, Xing Y, Scholz H, Schedl A 2004 The major podocyte protein nephrin is transcriptionally activated by the Wilms' tumor suppressor WT1. J Am Soc Nephrol 15:3044-3051

20. Call KM, Glaser T, Ito CY, Buckler AJ, Pelletier J, Haber DA, Rose EA, Kral A, Yeger H, Lewis WH, et al 1990 Isolation and characterization of a zinc finger polypeptide gene at the human chromosome 11 Wilms' tumor locus. Cell 60:509520

21. Gessler M, Poustka A, Cavenee W, Neve RL, Orkin SH, Bruns GA 1990 Homozygous deletion in Wilms tumours of a zinc-finger gene identified by chromosome jumping. Nature 343:774-778

22. Denys P, Malvaux P, Van Den Berghe H, Tanghe W, Proesmans W 1967 [Association of an anatomo-pathological syndrome of male pseudohermaphroditism, Wilms' tumor, parenchymatous nephropathy and XX/XY mosaicism]. Arch Fr Pediatr 24:729-739

23. Drash A, Sherman F, Hartmann WH, Blizzard RM 1970 A syndrome of pseudohermaphroditism, Wilms' tumor, hypertension, and degenerative renal disease. J Pediatr 76:585-593

24. Frasier SD, Bashore RA, Mosier HD 1964 Gonadoblastoma associated with pure gonadal dysgenesis in monozygous twins. J Pediatr 64:740-745

25. Pelletier J, Bruening W, Kashtan CE, Mauer SM, Manivel JC, Striegel JE, Houghton DC, Junien C, Habib R, Fouser L, et al 1991 Germline mutations in the Wilms' tumor suppressor gene are associated with abnormal urogenital development in Denys-Drash syndrome. Cell 67:437-447

26. Ruf RG, Schultheiss M, Lichtenberger A, Karle SM, Zalewski I, Mucha B, Everding AS, Neuhaus T, Patzer L, Plank C, Haas JP, Ozaltin F, Imm A, Fuchshuber A, Bakkaloglu A, Hildebrandt F; 2004 Prevalence of WT1 mutations in a large cohort of patients with steroid-resistant and steroid-sensitive nephrotic syndrome. Kidney Int 66:564-570

27. Royer-Pokora B, Beier M, Henzler M, Alam R, Schumacher V, Weirich A, Huff V 2004 Twenty-four new cases of WT1 germline mutations and review of the literature: genotype/phenotype correlations for Wilms tumor development. Am J Med Genet A 127:249-257

28. Maniatis TF, Sambrook J 1987 Molecular Cloning: A Laboratory Manual. 2nd Ed. Cold Spring Harbor, NY, Cold Spring Harbor Laboratory.

29. Arbeitsgemeinschaft fur Padiatrische Nephrologie 1988 Short versus standard prednisone therapy for initial treatment of idiopathic nephrotic syndrome in children. Arbeitsgemeinschaft fur Padiatrische Nephrologie. Lancet 1:380-383

30. Hoskins BE, Thorn A, Scambler PJ, Beales PL 2003 Evaluation of multiplex capillary heteroduplex analysis: a rapid and sensitive mutation screening technique. Hum Mutat 22:151-157

31. Baird PN, Cowell JK 1993 A novel zinc finger mutation in a patient with DenysDrash syndrome. Hum Mol Genet 2:2193-2194

32. Baird PN, Santos A, Groves N, Jadresic L, Cowell JK 1992 Constitutional mutations in the WT1 gene in patients with Denys-Drash syndrome. Hum Mol Genet 1:301305

33. Maiti S, Alam R, Amos CI, Huff V 2000 Frequent association of beta-catenin and WT1 mutations in Wilms tumors. Cancer Res 60:6288-6292

34. Stallmach T, Neuhaus TJ, Kosters R, Hailemariam S 1998 [Glomerulopathy in Denys-Drash syndrome. Case report of a model disease]. Pathologe 19:230-234

35. Bruening W, Bardeesy N, Silverman BL, Cohn RA, Machin GA, Aronson AJ, Housman D, Pelletier J 1992 Germline intronic and exonic mutations in the Wilms' tumour gene (WT1) affecting urogenital development. Nat Genet 1:144-148

36. Loirat C, Andre JL, Champigneulle J, Acquaviva C, Chantereau D, Bourquard R, Elion J, Denamur E 2003 WT1 splice site mutation in a 46,XX female with minimal-change nephrotic syndrome and Wilms' tumour. Nephrol Dial Transplant 18:823-825

37. Pritchard-Jones K, Rahman N, Gerrard M, Variend D, King-Underwood L 2000 Familial Wilms tumour resulting from WT1 mutation: intronic polymorphism causing artefactual constitutional homozygosity. J Med Genet 37:377-379

38. Kaplinsky C, Ghahremani M, Frishberg Y, Rechavi G, Pelletier J 1996 Familial Wilms' tumor associated with a WT1 zinc finger mutation. Genomics 38:451-453

39. Denamur E, Bocquet N, Mougenot B, Da Silva F, Martinat L, Loirat C, Elion J, Bensman A, Ronco PM 1999 Mother-to-child transmitted WT1 splice-site mutation is responsible for distinct glomerular diseases. J Am Soc Nephrol 10:2219-2223 